\section{ANALES DEL INSTITUTO DE INVESTIGACIONES ESTETICAS}

Anales del Instituto de Investigaciones

\section{Estéticas}

ISSN: 0185-1276

iieanales@gmail.com

Instituto de Investigaciones Estéticas

México

ZÁRATE SÁNCHEZ, EDÉN MARIO

Andrés de Concha y la capilla de San Gregorio Taumaturgo

Anales del Instituto de Investigaciones Estéticas, vol. XXXII, núm. 97, 2010, pp. 131-144

Instituto de Investigaciones Estéticas

Distrito Federal, México

Disponible en: http://www.redalyc.org/articulo.oa?id=36919259005

- Cómo citar el artículo

- Número completo

- Más información del artículo

- Página de la revista en redalyc.org

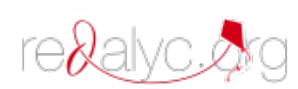

Sistema de Información Científica

Red de Revistas Científicas de América Latina, el Caribe, España y Portugal Proyecto académico sin fines de lucro, desarrollado bajo la iniciativa de acceso abierto 


\author{
EDÉN MARIO ZÁRATE SÁNCHEZ \\ INSTITUTO DE INVESTIGACIONES ESTÉTICAS, UNAM
}

\title{
Andrés de Concha y la capilla de San Gregorio Taumaturgo
}

AS PRIMERAS NOTICIAS DE LA VIDA y la obra de Andrés de Concha, quien estuvo activo en la Nueva España entre I550 y I6I I, las dio a conocer Manuel Toussaint en $1927^{\mathrm{I}}$ y desde entonces muchos historiadores han escrito al respecto. Gracias a los aportes de Toussaint y de los que le han sucedido en las investigaciones, conocemos más de ese artífice, testigo y actor del arte novohispano.

Más allá del carácter discutible de las afirmaciones acerca de la especialidad profesional de De Concha, el valor de ellas radica en la información que han aportado acerca del artista sevillano, pues poco a poco se han ido acumulando más datos que revelan su tránsito al Nuevo Mundo y las relaciones sociales que cultivó y le permitieron demostrar que era un artista prominente. ${ }^{2}$ En algunos artículos se ha reconocido la obra de nuestro artista no sólo como la de un

I. Manuel Toussaint, "Notas sobre Andrés de la Concha”, Revista Mexicana de Estudios Históricos, t. I, núm. I, I927. Es importante resaltar que Toussaint lo llama Andrés de la Concha y otros investigadores Andrés de Concha. Sin embargo, no hay suficientes documentos con su firma autógrafa que permitan establecer su nombre real. Aquí se usará Andrés de Concha, tal como el nombre figura en el "Anexo documental" incluido al final del presente ensayo.

2. Carmen Sotos Serrano, "Luces y sombras en torno a Andrés y Pedro de Concha", Anales del Instituto de Investigaciones Estéticas, vol. XXV, núm. 83, otońo de 2003, pp. I 23-I 52; "De artistas y mecenas: Andrés de la Concha y sus relaciones con la sociedad novohispana", Memorias de la Academia Mexicana de la Historia correspondiente de la Real de Madrid, t. XLVIII, 2007-2008. 
importante pintor, sino también de un arquitecto, ${ }^{3}$ tallador ${ }^{4} \mathrm{y}$, últimamente, tracista. $^{5}$

No es nuestra intención repetir lo escrito sobre el mencionado artífice; además, acerca de su vida es poco lo que se podría agregar: el hallazgo de su testamento podría confirmar y complementar los datos disponibles sobre él, pero aún no se ha localizado y consideramos que poco cambiaría lo que ya se sabe. Es, sin embargo, su obra el tema que más dudas suscita. En el caso de la pintura, se le han adjudicado distintas obras en que no se ha localizado su firma; se presume su autoría a partir de las escrituras de concierto de obra que celebró con los contratantes en distintos lugares del virreinato. No obstante, no se sabe si en realidad toda la obra fue elaborada por él mismo o por el pincel de algún miembro de su taller. En el caso de la arquitectura ocurre lo mismo: en ciertos documentos se afirma que De Concha fue autor de una obra, pero sólo en una de ellas se ha localizado su firma. La realidad es que aún quedan muchas dudas acerca de la vida artística del personaje aquí investigado.

En el presente texto, intentaremos aportar otro dato sobre la obra del pintor, arquitecto, tallador y tracista sevillano que revela parte de su actividad artística en la primitiva Catedral de México durante los últimos ańos de su vida. Concretamente, se trata de su labor en la construcción del retablo de San Gregorio Taumaturgo, obra que se ubicó dentro de la capilla de la misma advocación en aquella catedral. La noticia, localizada por quien escribe estas líneas en los libros de las actas de cabildo del Archivo de la Catedral Metropolitana, se vuelve más relevante porque, junto a ella, también se ofrecen datos acerca de la construcción de la capilla, la fecha de inicio de su edificación, su constructor y el retablo, en el que participó De Concha.

3. Martha Fernández, Arquitectura y gobierno virreinal. Los maestros mayores de la ciudad de México. Siglo XVII, México, Universidad Nacional Autónoma de México-Instituto de Investigaciones Estéticas, I985.

4. José Guadalupe Victoria, "Sobre las nuevas consideraciones en torno a Andrés de la Concha", Anales del Instituto de Investigaciones Estéticas, vol. XIII, t. I, núm. 50, I982, pp. 77 y 86; Guillermo Tovar de Teresa, Pintura y escultura del Renacimiento en México, México, Instituto Nacional de Antropología e Historia, I979; este autor también le adjudica dotes de "dorador o ensamblador": véase Guillermo Tovar de Teresa, Renacimiento en México. Artistas y retablos, México, Secretaría de Asentamientos Humanos y Obras Públicas, I982, p. I 44.

5. Sotos Serrano, "De artistas y mecenas...", loc. cit., p. 40. 


\section{San Gregorio Taumaturgo}

San Gregorio El Taumaturgo (213-270 ca.) nació en Neocesarea del Ponto, donde estudió retórica y derecho; en Cesarea de Palestina asistió a los cursos que Orígenes (185-252/254 ca.) impartía; a partir de estos cursos, Gregorio se convirtió al cristianismo. Aunque escribió varias obras, el Discurso de agradecimiento a Orígenes "es uno de los más completos e interesantes sobre la historia de la educación cristiana"; 6 poco se sabe del porqué de su sobrenombre, Taumaturgo, que significa "el que hace milagros".

\section{El retablo de San Gregorio Taumaturgo}

El primero en dar noticias del retablo fue Toussaint en su obra Pintura colonial; en ésta, el autor comenta: "por acta de cabildo del Ayuntamiento, del 8 de noviembre [de I6Io] sabemos que [Andrés de Concha] hizo el retablo de San Gregorio Taumaturgo, para la capilla de dicho santo, que costeaba el Ayuntamiento"; 7 según este autor, el I ${ }^{\circ}$ de noviembre de I6I I De Concha no había terminado la obra y pedía que se le pagara lo que le restaba; por tanto, el cabildo de la ciudad determinó que dos pintores revisaran la obra y la tasaran para determinar lo correspondiente. ${ }^{8}$ Este dato fue confirmado después por Martha Fernández en su artículo "Andrés de Concha: nuevas noticias, nuevas reflexiones", 9 donde cita las actas de cabildo del ayuntamiento de la ciudad de México e informa que la fábrica del retablo mayor de la capilla de San Gregorio estuvo a cargo de De Concha desde el 8 de noviembre de I6ı, pero que, en I6I I, la obra no se había concluido por ciertos adeudos con el artífice. ${ }^{\text {I0 }}$ Sin embargo, puede afirmarse, como estableceremos más adelante, que los trabajos en el retablo comenzaron en

6. Luis Ramos, La educación en la época medieval, México, Secretaría de Educación Pública, I985, pp. 59-60.

7. Manuel Toussaint, Pintura colonial, México, Universidad Nacional Autónoma de MéxicoInstituto de Investigaciones Estéticas, I990, p. 69.

8. Idem.

9. Martha Fernández, "Andrés de Concha: nuevas noticias, nuevas reflexiones", Anales del Instituto de Investigaciones Estéticas, vol. XV, núm. 59, I988, pp. 5 I-68. Cabe reiterar que las actas de cabildo del ayuntamiento de la ciudad de México ofrecen más noticias sobre la capilla de San Gregorio; las que aquí se publican son las del Archivo del Cabildo de la Catedral Metropolitana, correspondientes a los primeros ańos del siglo XVII.

Iо. Ibidem, p. 54. 
I608, cuando el cabildo de la Catedral dispuso que el mayordomo de fábrica se concertara con De Concha para la traza de dicho retablo.

Guillermo Tovar de Teresa también se pronunció acerca de la elaboración de un retablo para la capilla de San Gregorio Taumaturgo. Aunque afirma que en I603 Andrés de Concha proyectó dicho retablo para la catedral primitiva de México, ${ }^{\mathrm{II}}$ poco se sabe de dónde pudo obtener el dato, y desde nuestro punto de vista, fundado en los documentos que aquí se presentan, resulta imposible que el retablo de 1603 sea el mismo que se menciona de I6Io, por las razones adelante señaladas.

\section{La fábrica de la capilla y el retablo}

La capital de la Nueva España pasó los primeros años del siglo xviI padeciendo inundaciones, una de ellas causada por las grandes precipitaciones pluviales del verano de i607. En ese año, el ayuntamiento de la ciudad de México aceleró los trabajos del desagüe. Así, Enrico Martínez propuso ante la Real Audiencia de México un proyecto para desaguar la capital, donde se incluía la idea de evitar que las aguas del río Cuautitlán entraran a la laguna de Zumpango, al norte del valle de México, y que fueran desviadas hacia Huehuetoca y Nochistongo para darles salida por el río Tula. ${ }^{22}$ El proyecto era ambicioso y caro. Por ello, el ayuntamiento de la ciudad solicitó la ayuda del cabildo de la Catedral metropolitana, que decidió brindar el apoyo requerido para evitar las severas inundaciones.

Sin embargo, la ayuda ofrecida por la Catedral para el resguardo de la ciudad no fue sólo material y técnica, sino también celestial. Así, el ro de noviembre de 1607 , al encontrarse la sede vacante, el deán y cabildo determinaron dar paso a la petición, presentada por el cabildo del ayuntamiento, de

I I. Tovar de Teresa, Renacimiento en México, op. cit., p. I I 8. La primera noticia que se tiene de este santo en las actas de cabildo de la ciudad de México es de I604, cuando dicho cabildo había comisionado a dos regidores para que vieran lo referente a la fiesta de san Gregorio Taumaturgo, abogado del agua; sin embargo, este asunto no se volvió a tratar hasta I607; apud María Isabel Monroy Padilla, Guía de las actas de Cabildo de la ciudad de México, México, Departamento del Distrito Federal-Secretaría General de Desarrollo Social-Comité Interno de Ediciones Gubernamentales/Universidad Iberoamericana, I987, p. I7 I.

I 2. Jorge Gurría Lacroix, El desagüe del valle de México, México, Universidad Nacional Autónoma de México, I978, pp. 50-87. 
que "se guarde en esta ciudad la fiesta del glorioso san Gregorio Taumaturgo y se reciba por patrón y abogado della" ${ }^{13}$ La finalidad de tomar como patrón y abogado a este santo era que los librara de la gran inundación que por esa fecha azotaba a la ciudad. Así, su fiesta se consideró una de las más solemnes, por lo que, a partir del is de ese mismo mes y año, san Gregorio Taumaturgo fue alzado como patrón y abogado de la capital. ${ }^{14}$

Para ensalzar su culto era necesario un espacio donde se realizara el ritual; por tanto, fue indispensable construir una capilla en la primitiva Catedral. Las actas del cabildo de ésta no registran con exactitud la fecha en que se puso la primera piedra, pero el is de abril de 1608 los trabajos ya habían comenzado. Ese mismo día, el cabildo catedralicio había celebrado su primera junta, pasada la Pascua de Resurrección. En la reunión se trató sobre los avances de la construcción y se dispuso que la obra quedara a cargo del tesorero don Juan de Salamanca, en nombre del virrey. ${ }^{\text {IS }}$

El i8 de noviembre de 1608 , los trabajos en la capilla no habían tenido aún grandes avances. El maestro a cargo había sido el arquitecto Alonso Pérez Carvallo, quien también fungía como mayordomo de la fábrica de la Catedral y obrero mayor - función que desempeñó desde el 23 de septiembre de ese año, a causa del fallecimiento del anterior obrero mayor, el maestro carpintero Bartolomé Díaz. ${ }^{16}$ En este cabildo se trató el atraso de la construcción, pero lo más importante fue el hecho de que el cabildo y regimiento de la ciudad la habían descuidado, a pesar de que se habían ofrecido a "erigir, proseguir y concluir la obra". Por tanto, se resolvió que, debido a la urgencia y a la necesidad de que san Gregorio sirviera como intercesor, los costos de las labores quedarían a

I3. Archivo del Cabildo de la Catedral Metropolitana (en adelante ACСM), Actas de Cabildo, lib. 5, f. 6Iv. Véase el "Anexo documental". El 28 de septiembre de I607, el cabildo de la ciudad de México comisionó a Baltasar Guillén de Herrera y a Francisco Trejo Carvajal para que hablaran con el cabildo catedralicio, con el fin de que éste encargase a su vez a dos personas el cumplimiento del deseo del virrey: formar la hermandad y la capilla de San Gregorio, donde se celebraría el día de este santo, al que se tomaría como patrón y abogado de los daños que causan las aguas; Monroy Padilla, op. cit., p. 293.

I 4. AСCM, Actas de Cabildo, lib. 5, ff. 62-62v. Véase el "Anexo documental". De hecho, el ayuntamiento pidió al procurador mayor Francisco de Solís que, junto con el cabildo de la catedral, elaborara la escritura en que ambos ayuntamientos se obligaban a adornar la capilla y celebrar su festividad. Apud Monroy Padilla, op. cit., p. 298.

I 5. ACCM, Actas de Cabildo, lib. 5, f. 80. Véase el "Anexo documental".

I6. Ibidem, f. $98 \mathrm{v}$. 
cargo de la fábrica material de la Santa Iglesia y que su mayordomo, Francisco de Paz, solicitaría al obrero Carvallo que la "concluyera y acabara". ${ }^{17}$

En ese mismo cabildo, se encomendó al mayordomo que tratara con

Andrés de Concha, pintor y maestro mayor que es de la obra desta Santa Iglesia, por nombramiento de su excelencia y de los señores presidente y oidores desta Real Audiencia, para que haga un dibujo, tanteo y montea del retablo que se ha de hacer del glorioso santo para la dicha capilla, y con toda brevedad, habiendo hecho el tal dibujo, lo traiga a este cabildo y tratado con el dicho Andrés de Concha el último precio y costa que ha de tener, para que visto y entendido lo que más convenga; y que en todo acaecimiento tenga el debido efecto que se pretende [en] la dicha capilla y retablo, se trate y determine por los dichos seńores. ${ }^{18}$

De esta manera, el cabildo catedralicio se hizo cargo de los gastos, tanto de la capilla como del retablo de San Gregorio Taumaturgo, y delegó la responsabilidad de la primera en el arquitecto Alonso Pérez Carvallo y de la segunda en el pintor y maestro mayor de la Catedral, nombrado así por el ayuntamiento, Andrés de Concha, lo cual se ratificó en la sesión del 2I de noviembre de ese año. ${ }^{19}$

En vista de esta resolución, el ayuntamiento de la ciudad quiso compensar el descuido en que se había incurrido al preparar la capilla, así que el 28 de noviembre de 1608 envió al arzobispo una carta que se leyó ante el cabildo catedralicio, cuando celebraba su reunión, redactada en estos términos:

Ilustrísimo señor. Lo que el cabildo desta ciudad ha tratado con el desta Santa Iglesia, que es quedando capilla y celebrando la fiesta del santo, de vísperas y misa, y obligándose a señalar capilla en la iglesia nueva, ${ }^{20}$ el cabildo desta ciudad se obligará a hacer el retablo, reja, colgaduras y ornamentos y todo lo más necesario para que esté la

I7. Ibidem, ff. I04V.-I05. El 20 de octubre de I608, el ayuntamiento comisionó a Francisco de Trejo Carvajal para que organizara la fiesta y, junto con Baltasar Guillén de Herrera, tratara sobre los "asientos" de la capilla con el cabildo eclesiástico y el arzobispo; el gasto que ello ocasionara correría a cargo de "propios". Apud Monroy Padilla, op. cit., p. 332.

I 8. Idem (cursivas del autor).

I9. ACCM, Actas de Cabildo, lib. 5, f. I05v.

20. Al parecer se refiere a la Catedral, que comenzó a construirse en I 57I. Sin embargo, no hemos localizado ningún registro que confirme la existencia de un espacio reservado para esta capilla en la "iglesia nueva". 
dicha capilla decente y bien adornada. Suplica la ciudad a vuestra seńoría Ilustrísima, se sirva acabarlo en la forma que fuere servido para que luego se ponga por obra. ${ }^{21}$

La carta generó discusión entre los miembros del cabildo. El descuido del ayuntamiento respecto a la obra había provocado que las dignidades eclesiásticas desconfiaran del apoyo que aquél les brindaba. La mayoría votó a favor de que los gastos, tanto de la capilla como del retablo, corrieran por cuenta de la Catedral: "así lo habían ofrecido y así lo ofrecían una vez más". Sin embargo, el arzobispo les replicó que era muy importante —y por el bien de la república- recibir la ayuda de los comisarios y regimiento de la ciudad; por tanto, los miembros del cabildo dispusieron que si tal era la voluntad del prelado, que así se hiciese. ${ }^{22}$

Durante los siguientes cuatro meses prosiguió la obra de la capilla a cargo de la Catedral. No hemos localizado la escritura de donación que hicieron los comisarios y el regimiento metropolitano; no obstante, al parecer no se cumplió, pues el 26 de marzo de 1609 solicitaron al arzobispo que les concediese ser patrones de dicha capilla, solos o de manera conjunta con "su señoría y el deán y cabildo". La respuesta fue tajante:

Su señoría, con la mayor parte de todos los dichos señores fueron del acuerdo que no haya patronazgo alguno, fuera de su señoría y señores capitulares; y que la dicha capilla se concluya y acabe hasta ponerla en toda perfección, como está tratado y concertado, en nombre de los dichos señores, con los dichos maestros y artífices del edificio de la dicha capilla y retablo de la figura del glorioso sancto. Y que no se pongan [f. I I $8 \mathrm{v}$ ] sobre el dicho retablo otras armas, que un escudo muy bien tallado, en el que se ponga el dulce nombre de Jesús con la mayor gala, hermosura y lindeza que sea posible. ${ }^{23}$

El I4 de julio de I609, la capilla de San Gregorio aún no había sido terminada; sin embargo, el mayordomo de la obra de la Catedral, Francisco de Paz, fue compelido por el deán y cabildo para asegurarse de que la obra se concluyera

2 I. ACCM, Actas de Cabildo, lib. 5, ff. I06-i o6v. Por otra parte, el 2 de abril de I609, Francisco de Trejo Carvajal, comisionado por el ayuntamiento, recibió la orden de hacer las escrituras necesarias para el ornato de la capilla y el retablo, pero éstas no se conocen. Apud Monroy Padilla, op. cit., p. 364 .

22. Idem.

23. ACCM, Actas de Cabildo, lib. 5, ff. i i 8-i I 8v. Véase el "Anexo documental" (cursivas del autor). 
y se colocara en ella — mientras se reparaba el Sagrario - el Santísimo Sacramento, con el fin de llevarlo desde allí a los enfermos. ${ }^{24}$

Hasta aquí hemos visto que la construcción de la capilla de San Gregorio Taumaturgo se inició en I608 y que hasta julio de I609 aún se hallaba inconclusa. Las actas del cabildo de la Catedral metropolitana no registran cuándo se terminó. Sin embargo, la última noticia consignada en ellas al respecto es que el 7 de septiembre de I6I I se compraron dos carretadas de cal para "aderezar la azotea alta de la Santa Iglesia y las capillas de Santo Crucifijo y San Gregorio", 25 lo cual significa que en tal fecha ya se había finalizado la capilla.

Acerca de su ubicación dentro del recinto catedralicio, poco se sabe. Los documentos no dan noticia de ello. Manuel Toussaint afirma que hasta I 588 había dos capillas: la del Bautisterio y Sacramento y la del Santo Crucifijo. También había ocho altares: el de santa Ana, el de los Ángeles, el de san Bartolomé, el llamado de las Indulgencias; otro de san Jerónimo, el de san Cristóbal y el "altar que está junto a la sacristía”. ${ }^{26}$ Esto nos permite suponer que la capilla de San Gregorio fue la tercera y que posiblemente se situó cerca del altar mayor. Por otro lado, recordemos que se determinó colocar en esta capilla el Santísimo Sacramento, mientras se reparaba el Sagrario. ¿Habrá sido por su cercanía al Altar Mayor o por la importancia que pretendía darse a su culto? También podemos suponer que debió de estar junto a la capilla del Santo Crucifijo, pues, junto con la de San Gregorio, fue reparada en I6I I debido a los deterioros que había sufrido su azotea.

Respecto al retablo, ahora sabemos que el i 8 de noviembre de I608 el deán y cabildo solicitó a Francisco de Paz que se pusiera de acuerdo con Andrés de Concha, pintor y maestro mayor de la obra de la Santa Iglesia, para que hiciera el dibujo, tanteo y montea de aquél. Por tanto, por ningún concepto podría tratarse del retablo que, según Tovar de Teresa, en I603, el mismo artífice elaboró para la capilla de San Gregorio en la Catedral. No obstante,

24. Ibidem, f. I33v.

25. Ibidem, f. 246v. Las actas de cabildo del ayuntamiento sólo registran que a partir de la fecha se realizaba la fiesta del santo. La última noticia de la capilla en dichas actas se registró el 8 de noviembre de I6I 2, cuando el ayuntamiento pidió a Francisco de la Barrera que hablara con el sacristán mayor de la catedral para aderezar "el altar de la capilla de San Gregorio y [...poner] el adorno conveniente", apud Monroy Padilla, op. cit. (años I6I I-I629), p. I 22. Hay otras noticias, pero sólo se refieren a la compra de "luminarias" para la fiesta.

26. Manuel Toussaint, Paseos coloniales, México, Universidad Nacional Autónoma de MéxicoInstituto de Investigaciones Estéticas, 1962, pp. 2-3. 
ahora podemos afirmar que en la fecha indicada aún no se convertía en patrón de la ciudad a ese santo, el cual, además, no contaba todavía con un espacio dentro del recinto catedralicio, y mucho menos se celebraba en él la fiesta de su advocación.

Ahora bien, los problemas entre el cabildo de la Catedral y el de la ciudad continuaban, a tal punto que, el 9 de noviembre de I6ro, el ayuntamiento había solicitado a De Concha que, antes de finalizar la obra, le presentara el rótulo que habría de ponerse en el retablo para determinar si lo aprobaba, ${ }^{27}$ contradiciendo así lo que había ordenado el cabildo catedralicio el 26 de marzo de i609: que no hubiera más patrón que "su señoría y los señores capitulares". Sin embargo, en I6I I todavía no se terminaba el retablo debido a que el ayuntamiento aún adeudaba más de 300 pesos a Andrés de Concha. Evidentemente, la construcción del retablo referido muestra las desavenencias entre los dos cabildos. A causa de este conflicto, el culto a san Gregorio Taumaturgo, como patrono "del agua", no tuvo el realce esperado; tanto así que, años después, fue desplazado por una "nueva patrona del agua": la Virgen de Guadalupe.

Lamentablemente no sabemos —al igual que Martha Fernández-si el retablo fue concluido o no, y si se colocó en la capilla. Si bien en 1634 logró conservarse un retablo de San Gregorio que, de acuerdo con Toussaint, provenía de la "primitiva catedral", no podemos afirmar que fuera el que De Concha realizó. También es lamentable que no se conserven restos de él ni de la capilla. De lo que sí estamos seguros es de que Andrés de Concha hizo el dibujo, tanteo y montea de ese retablo, dedicado a san Gregorio Taumaturgo.

27. Fernández, "Andrés de Concha. Nuevas noticias...", op. cit., p. 54. 


\section{Anexo DocumentaL ${ }^{28}$}

[f. 6Iv]

Io de noviembre de 1607

[Fragmento del acta de cabildo donde se dispone que por solicitud del cabildo de la ciudad de México se reciba por patrón a san Gregorio Taumaturgo]

Habiendo entendido una petición que presentó el cabildo de esta ciudad en razón de que se guarde en esta ciudad la fiesta del glorioso san Gregorio Taumaturgo y se reciba por patrón y abogado della, dijeron que cometían y cometieron al señor doctor don Juan de Salamanca el hacer información de cómo convenía que se recibiese por tal patrón y abogado; y que fecha, se traiga a este cabildo para que se provea lo que más convenga.

Ante mí, Juan Hernández, secretario [rúbrica].

[ff. 62-62v]

I5 de noviembre de 1607

[Fragmento del acta de cabildo en la que se dispone que san Gregorio Taumaturgo sea el patrón de la ciudad de México y se celebre una fiesta doble]

Habiéndose traído la información que los dichos señores mandaron hacer por su auto de diez de noviembre en razón de que se guarde en esta ciudad la fiesta del glorioso san Gregorio Taumaturgo; y habiéndola visto y entendido lo mucho que importa [a] esta ciudad tomar por patrón y abogado al glorioso san Gregorio y celebrar [ilegible] su día para que mediante su intercesión con nuestro señor, esta ciudad sea libre de la grande inundación que al presente tiene, todos de un ánimo y acuerdo dijeron que permitían y tenían [f. 62v] por bien que, en esta ciudad, se guarde esta dicha fiesta tomando por patrón al bienaventurado San Gregorio; y como tal fiesta doble, se rece en esta dicha ciudad. Y así lo proveyeron y mandaron y lo firmó el señor presidente. De lo cual se despachó auto en forma este día para que se hiciese la publicación de esta fiesta.

Ante mí, Juan Hernández, secretario [rúbrica]

28. ассм, Actas de Cabildo, lib. 5 . 
[f. 8o]

I5 de abril de 1608

[Fragmento del acta de cabildo en que se determina que la capilla de San Gregorio Taumaturgo quede en manos del tesorero de su majestad]

Asimismo, propuso el señor tesorero don Juan de Salamanca, en nombre del Señor Virrey, el negocio de la capilla del glorioso san Gregorio Taumaturgo y se determinó por todos los dichos señores que, en cuanto al edificio della, se prosiga y que se le dé parte al señor virrey desto y de cómo su señoría lo pone todo en sus manos para que su excelencia ordene lo que fuere servido acerca de que haya cofradía [...].

Ante mí, Juan Hernández [rúbrica]

I8 de noviembre de I608

[ff. I04V-I05]

[Fragmento del acta de cabildo en que se dispone que Alonso Pérez Carvallo acabe la capilla y que acuerde con Andrés de Concha el dibujo, tanteo y montea del retablo de San Gregorio Taumaturgo]

Tratose por todos los dichos señores lo poco que el obrero Carvallo ha trabajado en concluir la obra que le está encargada de la capilla del glorioso San Gregorio Taumaturgo; y asimismo, de lo poco que el cabildo y regimiento desta ciudad solicitaba esta causa no embargante que, como consta por otros autos de este libro, se habían ofrecido a erigir y proseguir [f. IO5] y concluir la dicha obra; y porque no era ni es justo que parase sin proseguirla hasta acabarla, por muchas razones y causas, que por todos los dichos señores se propusieron y trataron con grande celo y ánimo de la edificación de toda esta república, y de animarla a la devoción del glorioso santo para que sirva de ser intercesor ante nuestro señor por esta ciudad y los vecinos y moradores della, y que la libre de otra inundación como la pasada y de otros trabajos, dijeron todos de un acuerdo ánimo y voluntad, que desde hoy dicho día, la dicha obra se prosiga con todo cuidado a costa de la hacienda de la fábrica desta Santa Iglesia, y que como mayordomo della el señor canónigo Francisco de Paz solicite al dicho obrero Carvallo, para lo que está a su cargo, lo concluya y acabe; y asimismo, le encargaron al dicho señor canónigo que trate con Andrés de Concha, pintor y maestro mayor que 
es de la obra desta Santa Iglesia, por nombramiento de su excelencia y de los señores presidente y oidores desta Real Audiencia, para que haga un dibujo, tanteo y montea del retablo que se ha de hacer del glorioso santo para la dicha capilla, y con toda brevedad, habiendo hecho el tal dibujo, lo traiga a este cabildo y tratado con el dicho Andrés de Concha el último precio y costa que ha de tener, para que visto y entendido lo que más convenga; y que en todo acaecimiento tenga el debido efecto que se pretende [en] la dicha capilla y retablo, se trate y determine por los dichos señores, consultándolo todo con su señoría Ilustrísima del señor Arzobispo. Y así lo proveyeron y mandaron.

Ante mí, Juan Hernández [rúbrica]

$$
\text { [ff. 106-106v] }
$$

28 de noviembre de 1608

[Fragmento del acta de cabildo en que se discute acerca del ofrecimiento del cabildo del ayuntamiento para hacer el retablo, reja, colgaduras y demás ornamentos necesarios para la capilla de San Gregorio Taumaturgo]

Su señoría Ilustrísima, habiéndosele consultado por los dichos señores deán y cabildo el estado en que tenían la capilla del glorioso San Gregorio Taumaturgo y la determinación de que se prosiguiese y acabase según que en el cabildo de I8 deste presente mes y ańo se contiene, propuso a los dichos señores un papel que de parte del cabildo y regimiento desta ciudad se le había presentado, el tenor del cual es como se sigue:

Ilustrísimo seńor. Lo que el cabildo desta ciudad ha tratado con el desta Santa Iglesia, que es quedando capilla y celebrando la fiesta del santo, de vísperas y misa, y obligándose a señalar capilla en la iglesia nueva, el cabildo desta ciudad se obligará a hacer el retablo, reja, colgaduras y ornamentos y todo lo más necesario para que esté la dicha capilla decente y bien adornada. Suplica la ciudad a vuestra señoría Ilustrísima, se sirva acabarlo en la forma que fuere servido para que luego se ponga por obra.

Y los dichos señores deán y cabildo, habiendo entendido lo que contenía el dicho memorial y estando con determinación de que la dicha capilla y todo lo a ella anexo y perteneciente se prosiguiese y acabase a costa de la dicha Santa Iglesia o a costa de los dichos señores prebendados que así lo habían ofrecido y de nuevo lo ofrecían, y su señoría Ilustrísima, mostrándose agradecido al ánimo 
y determinación que los dichos señores tenían, replicó lo mucho que importaba admitir el ofrecimiento de la ciudad para mayor servicio de nuestro señor y del glorioso santo que con esta tan santa obra en que concurrían ambos cabildos, era conveniente y muy importante se estableciese y confirmase una voluntad y amor en aumento de la devoción de toda esta república, y que así le parecía a su señoría Ilustrísima convenir que [f. Io6v] quedase a su cargo el tratar lo que más fuese a propósito, en razón de lo susodicho con los comisarios de la dicha ciudad y regimiento, a lo cual todos los dichos señores prebendados acudieron de un ánimo y acuerdo reagradeciendo a su señoría Ilustrísima el fervoroso ánimo con que emprendía la prosecución y conclusión de tan santa obra afirmándose los dichos señores en que si a su señoría Ilustrísima le pareciese que se prosiguiese y acabase a costa de ellos como lo tenían ofrecido, que así se hiciese; y pareciéndosele a su señoría otra cosa, que con esto venía con mucha voluntad y con esto se disolvió este cabildo, tomando su señoría Ilustrísima como dicho es a su cargo la prosecución de este negocio.

Juan Hernández [rúbrica]

26 de marzo de 1609

[ff. I I 8-II 8v]

[Fragmento del acta de cabildo donde se presenta la carta del cabildo de la ciudad de México en que solicita ser patrón de la capilla y registra la respuesta del cabildo catedralicio]

Este dicho día propuso su señoría Ilustrísima lo que había tratado con los comisarios del cabildo y regimiento de esta ciudad, en razón de la erección y dotación de la capilla del glorioso Sant Gregorio Taumaturgo, que esta sancta iglesia ha ido edificando a su costa, en honor del glorioso sancto, pretendiendo su intercesión ante nuestro señor, con todos los peligros que se puedan ofrecer de inundación de esta ciudad que se vido al tiempo que los dichos señores deán y cabildo, en sede vacante, determinaron invocar su auxilio, tomándole por patrón y abogado; y porque entre otras pretensiones que el dicho cabildo y regimiento ha tenido y tratado con su señoría Ilustrísima, se les concediese ser patrones por sí o juntamente con su señoría y señores deán y cabildo desta dicha Sancta Iglesia, de lo cual se podían seguir inconvenientes defectuosos de vencer. Su señoría, con la mayor parte de todos los dichos señores, fueron del acuerdo que no haya patronazgo alguno, fuera de su señoría y señores 
capitulares; y que la dicha capilla se concluya y acabe hasta ponerla en toda perfección, como está tratado y concertado, en nombre de los dichos señores, con los dichos maestros y artífices del edificio de la dicha capilla y retablo de la figura del glorioso sancto. Y que no se pongan [f. II 8v] sobre el dicho retablo otras armas, que un escudo muy bien tallado, en el que se ponga el dulce nombre de Jesús con la mayor gala, hermosura y lindeza que sea posible. Y así lo proveyeron y mandaron.

Juan Hernández [rúbrica]

[f. I33]

I4 de julio de 1609

[Fragmento del acta de cabildo donde se dispone que, mientras se repara el Sagrario, el Santísimo Sacramento sea llevado a la capilla de San Gregorio]

Otro sí, los dichos señores encargaron al señor canónigo Francisco de Paz, con toda la brevedad posible, haga que se acabe la obra de la capilla del glorioso Sant Gregorio Taumaturgo, para que, en el ínter que se acude al reparo de dicho Sagrario, los curas beneficiados dél pasen a la capilla del glorioso Sant Gregorio, el Santísimo Sacramento para que desde allí se les lleve a los enfermos y los dichos señores curas tengan lugar suficiente y capaz para el ejercicio de sus obligaciones y oficios. Y así lo proveyeron y mandaron.

Ante mí, Juan Hernández [rúbrica] 